\title{
HUBUNGAN KARAKTERISTIK DAN PENGETAHUAN REMAJA TENTANG ROKOK DENGAN PERILAKU MEROKOK REMAJA DI KULONPROGO YOGYAKARTA
}

Sujono Riyadi, Program Studi IImu Keperawatan Universitas jenderal Ahmad Yani e-mail: sujono_kmpk2005@yahoo.com

Dwi yati, Program Studi Ilmu Keperawatan Universitas jenderal Ahmad Yani

e-mail: dwie.ns215@gmail.com

Afi Lutfiyati, Program Studi Ilmu Keperawatan Universitas jenderal Ahmad Yani

e-mail: i_luth77@yahoo.com

\section{ABSTRACT}

Smoking is a habit that can provide pleasure for smokers themselves, but on the other hand can also cause negative impacts for the smokers themselves and for those around them. A person exposed to secondhand smoke (passive smokers) for eight hours is proportional to direct smoking of 20 cigarettes per day. The purpose of this research is to know the correlation of adolescent characteristic and knowledge about cigarette with teenage smoking behavior in Kulonprogo Yogyakarta

This research is quantitative by using analytic survey method with cross sectional approach, as many as 160 teenagers who smoke in Kulonprogo Regency Yogyakarta. Data collection by using questionnaire and analyzed by using Pearson correlation statistic test.

The results showed that the correlation coefficient between adolescent knowledge about smoking with teen smoking behavior in Kulonprogo Yogyakarta (-0.205). The correlation coefficient between adolescent age and teenage smoking behavior in Kulonprogo Yogyakarta amounted to $(0,472)$ and correlation coefficient between adolescent pocket money and teenage smoking behavior in Kulonprogo Yogyakarta $(0,412)$.

There is a relationship between adolescent age with teenage smoking behavior in Kulonprogo Yogyakarta. There is a relationship between adolescent pocket money and teenage smoking behavior in Kulonprogo Yogyakarta. The higher the adolescent knowledge about cigarettes then the behavior of adolescent smoking in Kulonprogo Yogyakarta will be lower.

Keywords: Knowledge, youth, pocket money and Behavior smoke

\section{PENDAHULUAN}

Program Perilaku hidup bersih dan sehat (PHBS) adalah salah satu bentuk upaya memberikan pembelajaran terhadap perseorangan, keluarga maupun kelompok serta masyarakat luas dengan cara berkomunikasi yang baik, menyampaikan informasi serta memberikan pendidikan dalam upaya meningkatkan derajat pengetahuan, sikap dalam berperilaku hidup bersih dan sehat. $\mathrm{Hal}$ ini dilakukan dengan cara pendekatan pimpinan, bina suasana dan pemberdayaan masyarakat. PHBS ini adalah langkah awal yang harus dilakukan oleh setiap individu untuk mencapai derajat kesehatan yang optimal. Keadaan badan dan jiwa yang sehat tidak sera merta terjadi secara instan, tetapi haruslah selalu diupayakan. Upaya ini harus dimulai dari menanamkan pola pikir sehat dari diri sendiri terlebih dahulu. Karena ini semua menjadi bentuk pertanggungjawaban kita kepada masyarakat luas, sehingga diperlukan usaha yang optimal dan harus dimulai dari diri sendiri.

Upaya PHBS merupakan wujud dalam rangka meningkatkan kesehatan masyarakat yang tinggi sebagai salah satu bentuk investasi terhadap pembangunan dan sumber daya manusia yang produktif. Hal ini dibutuhkan komitmen yang tinggi bagi setiap stakeholder untuk senantiasa selalu bersama-sama dan saling mendukung terhadap peningkatkan derajat kesehatan masyarakat dapat tercapai secara optimal. Data Riset Kesehatan Dasar 2013 melaporkan bahwa pencapaian rumah tangga Ber-PHBS secara nasional baru mencapai $36,18 \%$ dari target $42 \%$, sedangkan pencapaian rumah tangga ber-PHBS hasil Riskesdas di DIY sudah mencapai $52,4 \%$, namun masih ada beberapa indikator yang belum berhasil, salah satu dari indikator PHBS yang belum tercapai adalah tentang perilaku merokok ${ }^{1}$.

Indikator ketercapaian "tidak merokok di dalam rumah" di DIY masih rendah, hal ini berarti bahwa masyarakat di DIY masih banyak yang belum sadar akan pentingnya berperilaku hidup bersih dan sehat terutama berkaitan dengan perilaku yang berdampak pada kesehatan dirinya sendiri dan perilaku yang 
berdampak pada kesehatan orang lain yang diakibatkan oleh perilaku personal.

Kecenderungan perilaku merokok ini dari tahun ke tahun selalu menunjukkan angka prevalensi yang meningkat. Indonesia sendiri pada tahun 2008 menduduki peringkat ketiga dunia dalam hal konsumsi tembakau. Hasil survei $\mathrm{LM}_{3}$ (Lembaga menanggulangi masalah rokok), responden merokok secara aktif ada 375 orang, diantaranya ada $66,2 \%$ para perokok tersebut berusaha untuk berhenti merokok, akan tetapi usaha mereka untuk total tidak merokok gagal. Hal tersebut disebabkan karena berbagai macam sebab, diantaranya adalah karena faktor tidak tahu cara untuk berhenti merokok 42,9\%, karena sulit berkonsentrasi jika tidak merokok $25,7 \%$ dan juga karena faktor keterikatan dengan sponsor rokok sejumlah 2,9\%. Dalam survei ini pula disampaikan bahwa responden yang berhasil untuk berhenti dari berperilaku merokok karena faktor kesadaran sendiri sebanyak $76 \%$, dikarenakan sakit yang berhubungan dengan efek rokok $16 \%$ dan dikarenakan tuntutan profesi $8 \%{ }^{3}$.

Daerah Istimewa Yogyakarta (DIY) menduduki urutan ke empat secara nasional tentang masalah merokok ini $^{4}$. Hasil penelitian yang dilakukan oleh Pemkab Kabupaten Kulonprogo pada tahun 2017 bekerjasama dengan Nanyang Technology University diketahui bahwa dari 15.000 pelajar SMP yang ada di Kulonprogo, 800 remaja SMP (5,3\%) tersebut diantaranya adalah perokok. Hal ini

Tabel 1: Target dan Realisasi PHBS merupakan jumlah yang tergolong cukup tinggi, tidak bisa dibiarkan begitu saja dan harus dicarikan solusi terbaik agar jumlah tersebut bisa dikurangi ${ }^{5}$.

Pada masa remaja ini terjadi peralihan antara masa anak-anak ke masa dewasa. Kehidupan sosial dijenjang remaja ada tandatanda menonjolnya fungsi intelektual serta emosional. Keadaan ini menurut Erickson disebut sebagai masa krisis identitas, yaitu proses dalam pembentukan identitas diri serta konsep diri remaja yang sangat kompleks. Konsep diri remaja ini tidaklah hanya terbentuk dari bagaimana seorang remaja percaya tentang keberadaan dirinya sendiri, namun juga terbentuk dari kepercayaan orang lain akan keberadaan dirinya ${ }^{6}$.

Dalam perkembangannya, remaja akan menentukan jati dirinya dan memilih kawan akrabnya. Banyak remaja yang sangat percaya dengan kelompoknya dalam menemukan jati dirinya $^{7}$, dan dalam proses penemuan jati diri ini menurut Erickson seorang remaja didorong oleh sosiokultural ${ }^{6,8}$. Survey pada awal Januari 2018 yang dilakukan oleh peneliti masih banyak remaja (68\%) yang belum paham akan dampak merokok, mereka merokok karena faktor ikutikutan teman sekolahnya. Dengan adanya permasalahan ini maka peneliti tertarik untuk meneliti tentang hubungan karakteristik dan pengetahuan remaja tentang rokok dengan perilaku merokok remaja di Kabupaten Kulonprogo Yogyakarta.

\begin{tabular}{clccc}
\multicolumn{4}{c}{ Tabel 1: Target dan Realisasi PHBS Per-Indikator dan Komposit di DIY } \\
\hline \multirow{2}{*}{ No } & \multicolumn{1}{c}{ Indikator } & \multicolumn{2}{c}{ Tahun 2015 } & \multirow{2}{*}{ Keterangan } \\
\cline { 3 - 4 } & & Target & Realisasi & \\
\hline 1 & Persalinan ditolong oleh tenaga kesehatan & $99 \%$ & $99,3 \%$ & Tercapai \\
2 & Memberi bayi Air Susu Ibu (ASI) eksklusif & $80 \%$ & $61,8 \%$ & Belum tercapai \\
3 & Menimbang balita setiap bulan & $85 \%$ & $66,5 \%$ & Belum tercapai \\
4 & Menggunakan air bersih & $92 \%$ & $86,4 \%$ & Belum tercapai \\
5 & Mencuci tangan dengan air bersih dan sabun & $85 \%$ & $85,6 \%$ & Tercapai \\
6 & Menggunakan jamban sehat & $86 \%$ & $91,7 \%$ & Tercapai \\
7 & Memberantas jentik di rumah & $95,5 \%$ & $91,4 \%$ & Belum tercapai \\
8 & Makan sayur dan buah setiap hari & $50 \%$ & $15,6 \%$ & Belum tercapai \\
9 & Melakukan aktifitas fisik setiap hari & $90 \%$ & $55,8 \%$ & Belum tercapai \\
10 & Tidak merokok di dalam rumah & $48 \%$ & $39,1 \%$ & Belum tercapai \\
& Tatanan Rumah Tangga ber-PHBS (komposit) & $\mathbf{4 8 \%}$ & $\mathbf{2 , 1 \%}$ & Belum tercapai \\
\hline
\end{tabular}

\section{METODE}

Penelitian ini berbentuk penelitian kuantitatif, dimana dalam pelaksanaannya peneliti menggunakan metode survey analytic dengan pendekatan cross sectional, yaitu merupakan suatu penelitian yang menghubungkan antar variabel penelitian dengan cara menggunakan kuesioner yang diberikan pada responden yang nantinya dimungkinkan untuk dilakukan generalisasi ${ }^{9}$. Penelitian ini dilakukan di Kabupaten Kulonprogo Yogyakarta pada Bulan Februari - 
Maret 2018. Pertimbangan memilih Kabupaten Kulonprogo dikarenakan jumlah remaja yang merokok cukup tinggi, yaitu ada 800 remaja yang masih sekolah di sekolah menengah pertama ${ }^{5}$. Sampel yang kami gunakan sebanyak $20 \%$ yaitu ada 160 remaja yang merokok di Kulonprogo.

Teknik pengambilan sampling peneliti menggunakan stratified random sampling yaitu merupakan teknik pencuplikan dengan cara membagi populasi sasaran dalam strata (sub populasi). Lebih lanjut peneliti melakukan teknik proportional random sampling agar semua unit dapat terwakili secara proporsional berupa remaja yang merokok baik itu remaja awal, remaja pertengahan maupun remaja akhir. Analisis data peneliti menggunakan uji korelasi Pearson dengan menggunkan komputer program SPSS for windows versi 22.

\section{HASIL PENELITIAN}

Hasil penelitian tentang hubungan karakteritik dan pengetahuan remaja tentang rokok dengan perilaku merokok remaja dapat dilihat dalam beberapa tabel berikut ini.

Tabel 2: Distribusi frekuensi karakteristik remaja berdasarkan jenis kelamin, umur dan uang saku remaja di Kulonprogo Yogyakarta

\begin{tabular}{|c|c|c|c|}
\hline $\begin{array}{l}\mathbf{N} \\
0\end{array}$ & Jenis kelamin & $\mathbf{F}$ & (\%) \\
\hline \multirow[t]{3}{*}{1} & Laki-laki & 160 & $100 \%$ \\
\hline & Perempuan & 0 & $0 \%$ \\
\hline & Total & 160 & $100 \%$ \\
\hline \multirow[t]{5}{*}{2} & Umur remaja: & $\mathrm{F}$ & $\%$ \\
\hline & 1. Remaja awal (10-13 th) & 19 & $12 \%$ \\
\hline & $\begin{array}{l}\text { 2. Remaja pertengahan } \\
\text { (14-16 th) }\end{array}$ & 94 & $59 \%$ \\
\hline & 3. Remaja akhir (17-20 th) & 47 & $29 \%$ \\
\hline & Total & 160 & $100 \%$ \\
\hline \multirow[t]{5}{*}{3} & Uang saku remaja & & \\
\hline & Kurang Rp. $15.000 /$ hari & 136 & $85 \%$ \\
\hline & $\begin{array}{l}\text { Antara Rp. } 15.000 \text { - Rp. } \\
25.000 / \text { hari }\end{array}$ & 16 & $10 \%$ \\
\hline & Lebih dari Rp. $25.000 /$ hari & 8 & $5 \%$ \\
\hline & Total & 160 & $100 \%$ \\
\hline
\end{tabular}

Sumber: Data primer diolah 2018

Dalam tabel 2 dapat dilihat bahwa karakteristik remaja yang berperilaku merokok di Kabupaten Kulonprogo Yogyakarta apabila dilihat dari jenis kelaminnya 100\% laki-laki, apabila kita lihat dari segi umur mayoritas perokok adalah remaja berumur antara 14-16 tahun (remaja pertengahan), kemudian remaja akhir ada 29\% (umur 17-20 tahun) dan remaja awal (usia 10-13 tahun) ada 12\%. Remaja perokok apabila kita lihat dari uang saku setiap sekolah mayoritas uang sakunya adalah kurang dari Rp. 15.000/hari ada 85\%, uang saku antara Rp. 15.000/hari-Rp. 25.000/hari ada $10 \%$ dan uang saku lebih dari Rp. 25.000/hari ada $5 \%$.

Tabel 3: Distribusi frekuensi karakteristik remaja berdasarkan pengetahuan remaja tentang rokok di Kulonprogo Yogyakarta

\begin{tabular}{|c|c|c|c|}
\hline No & Pengetahuan Remaja & $\mathbf{F}$ & $(\%)$ \\
\hline 1 & Rendah & 75 & $47 \%$ \\
\hline 2 & Tinggi & 85 & $53 \%$ \\
\hline & Total & 160 & $100 \%$ \\
\hline
\end{tabular}

Sumber: data primer diolah 2018

Dari tabel 3 diatas diketahui bahwa tingkat pengetahuan remaja tentang rokok yang ada di Kulonprogo Yogyakarta relatif tinggi yaitu ada $53 \%$ dan remaja yang berpengetahuan rendah tentang rokok ada $47 \%$.

Tabel 4: Distribusi frekuensi karakteristik remaja berdasarkan perilaku merokok remaja di Kulonprogo Yogyakarta

\begin{tabular}{clcc}
\hline No & Perilaku merokok & $\mathbf{F}$ & $\mathbf{( \% )}$ \\
\hline 1 & Perokok ringan & 124 & $77 \%$ \\
2 & Perokok sedang & 33 & $21 \%$ \\
3 & Perokok berat & 3 & $2 \%$ \\
& Total & $\mathbf{1 6 0}$ & $\mathbf{1 0 0 \%}$ \\
\hline
\end{tabular}

Sumber: data primer diolah 2018

Pada tabel 4 ini mayoritas remaja yang ada di Kulonprogo Yogyakarta dikategorikan sebagai perokok ringan yaitu ada $77 \%$, dikategorikan sebagai perokok sedang ada $21 \%$ dan dikategorikan sebagai perokok berat ada $2 \%$.

Tabel 5: Hasil uji korelasi Pearson antara karakteristik remaja yang meliputi pengetahuan remaja tentang rokok, umur dan uang saku remaja dengan perilaku merokok remaja di Kulonprogo Yogyakarta

\section{No Perilaku merokok Koefisien korelasi} Remaja

\begin{tabular}{|c|c|c|}
\hline 1 & $\begin{array}{l}\text { Pengetahuan } \\
\text { Remaja }\end{array}$ & $-0,205^{* *}$ \\
\hline 2 & Umur remaja & $0,412^{* *}$ \\
\hline 3 & Uang saku remaja & $0,472^{* *}$ \\
\hline
\end{tabular}

Correlation is significant at the 0,01 level (2tailed)

Sumber: data primer diolah 2018 
Hasil uji statistiK dengan memakai pearson correlation didapatkan hasil bahwa ada hubungan yang sigifikan negatif antara pengetahuan remaja tentang rokok dengan perilaku merokok remaja di Kulonprogo Yogyakarta dengan nilai koefisien korelasi ($0,205)$, artinya bahwa semakin tinggi tingkat pengetahuan remaja tentang rokok maka semakin rendah perilaku merokok remaja tersebut. Hasil uji korelasi antara umur remaja dengan perilaku merokok didapatkan hasil koefisien korelasi $(0,412)$ yang menunjukkan ada hubungan, artinya bahwa ada semakin dewasa umur seorang remaja maka akan semakin tinggi perilaku merokoknya. Hasil uji korelasi antara uang saku remaja dengan perilaku merokok remaja didapatkan hasil ada hubungan dengan nilai koefisien korelasi $(0,472)$ yang berarti bahwa semakin banyak uang saku remaja maka akan semakin sering remaja tersebut untuk berperilaku merokok.

\section{PEMBAHASAN}

Usia remaja diharapkam mulai berfikir terhadap berbagai permasalahan yang jangkauannya jauh ke masa depan. Hakikatnya pada masyarakat yang akan remaja masuki nantinya di kemudian hari. Dalam proses kognitif ini biasanya mengarah pada sesuatu yang idealisme dan utopianisme, mereka akan selalu memegang hal-hal yang prinsip dan ideal, biasanya prinsip tersebut masih sangat abstrak seperti kebebasan, keadilan dan cinta, dan mereka (remaja) menjadi seorang pemimpi, mengkontruksi teori-teori tentang dunia yang lebih baik $^{8}$. Dalam penelitian ini, remaja yang berperilaku merokok di Kabupaten Kulonprogo yang menjadi responden secara acak kebetulan 100\% laki-laki. Walaupun tidak menutup kemungkinan ada pula remaja perempuan yang merokok, namun tidaklah sebanyak remaja laki-laki, mereka para remaja perempuan biasanya sangat soft (tidak terangterangan) dalam berperilaku merokok. Usia remaja perokok relatif masih muda, mayoritas masuk dalam kategori remaja pertengahan (1416 tahun).

Hal ini sesuai dengan penelitian yang dilakukan oleh Pemkab Kulonprogo tahun 2017 bahwa rata-rata remaja merokok pertama kali pada usia 13-16 tahun dengan jumlah populasi hampir 36\%. Awal merokok remaja di Kulonprogo karena faktor coba-coba, pengaruh lingkungan dengan salah satu contoh adanya budaya jamuan atau saat ada hajatan di desa yang selalu disediakan rokok dan asbak ${ }^{5}$. Remaja yang tinggal di kawasan pedesaan (pegunungan) terlihat percaya diri dengan cara merokok dibandingkan dengan remaja yang tinggal di perkotaan. Pengaruh lingkungan bisa berupa ${ }^{10}$ : (a) lingkungan alam / luar (external of physical environment), (b) lingkungan dalam (internal environment) dan (c) lingkungan sosial / masyarakat (social environment). Faktor risiko lain remaja untuk menjadi perokok disebabkan karena faktor psikologik, faktor biologik dan faktor lingkungan serta regulasi atau peraturan tentang penjualan rokok ${ }^{11}$.

Pengetahuan remaja tentang bahaya rokok mayoritas tinggi yaitu ada 53\%, sedangkan yang tingkat pengetahuannya rendah ada $47 \%$. Remaja yang perokok ringan ada $77 \%$, perokok sedang ada $21 \%$ dan perokok berat ada $2 \%$. Hasil uji statistic mengatakan bahwa ada hubungan negatif, yang berarti bahwa semakin tinggi tingkat pengetahuan remaja tentang bahaya merokok, maka akan semakin rendah keinginan remaja untuk berperilaku merokok. Hal ini tentunya butuh waktu untuk membuat remaja semakin sadar akan dampak dan bahaya dari merokok terutama bagi kesehatan tubuh perokok itu sendiri maupun orang lain mendapatkan dampaknya (perokok pasif). Konsekuensi dari merokok antara lain meningkatnya kejadian infeksi saluran bagian atas (ISPA), batuk, asma, bronchitis, pneumonia, empishema / PPOK (penyakit paru obstruksi kronis), TB paru, sinusitis, penyakit kardiovaskular, kanker, mengganggu fertilitas, lahir kurang bulan (BBLR), kematian maupun absen dari kerja / sekolah ${ }^{11,12,13}$. Dibutuhkan strategi untuk melakukan promosi kesehatan pada remaja, diantaranya melalui komunikasi untuk perubahan perilaku (KPP). KPP dilaksanakan untuk memperbaiki perilaku kesehatan masyarakat dan menekankan pada perubahan perilaku yang tidak hanya berhenti pada peningkatan pengetahuan dan sikap saja, melainkan dengan menggunakan berbagai saluran media baik media cetak maupun elektronik.

Komunikasi kesehatan melalui media yang dilakukan selama ini, belum optimal dalam mengubah atau memperbaiki perilaku masyarakat. Departemen Kesehatan Republik Indonesia telah menyusun program promosi kesehatan yang telah ditetapkan sebagai program unggulan pemerintah ${ }^{14}$. Promosi kesehatan dalam hal ini bertujuan untuk: (1) meningkatkan kesadaran serta kepedulian pada masyarakat Indonesia untuk selalu hidup sehat (2) melakukan pengembangan kemitraan serta pemberdayaan masyarakat yang untuk 
mencapai ini semua diperlukann upaya peningkatan promosi kesehatan. Upaya pencegahan terhadap masalah perilaku merokok dengan cara pendekatan psikososial yaitu: (1) pendekatan pengaruh sosial (social influences approach), remaja perlu diajarkan cara untuk menahan tekanan sosial terhadap merokok yang bisa datang darimana saja, misalnya datang dari orangtua sendiri, saudara kandung, teman maupun dari media. (2) melalui pendekatan melatih cara menghadapi kehidupan (life skills training approach), dimana remaja terkadang mengalami kemunduran diri (deficit personal), sehingga diperlukan adanya pelatihan/ bimbingan untuk melatih agar para remaja lebih percaya diri, tidak rendah diri, bisa berkomunikasi dan berinteraksi sosial dengan baik, mampu menghadapi stres sehingga tidak mudah terseret kearah perilaku negatif merokok ${ }^{11}$.

Umur remaja semakin dewasa akan semakin tinggi untuk berperilaku merokok. Padahal kalau di lihat dari segi pendapatan, masih banyak remaja yang belum mandiri secara ekonomi. Mereka masih mengandalkan pemberian dari orang tua yang berupa uang saku setiap hari mereka sekolah. Makin banyak uang saku yang mereka dapatkan dari orangtuanya, maka akan semakin tinggi pula keinginan untuk berperilaku merokok. Karena untuk mendapatkan rokok harus dengan membeli, dan untuk membeli rokok tersebut membutuhkan uang. Nah, dengan adanya uang saku yang banyak akan memudahkan para remaja untuk mengalokasikan uang saku tersebut untuk membeli rokok baik secara eceran maupun secarah utuh satu bungkus. Bahkan, tidak punya uang sekalipun remaja yang kecanduan rokok ini bisa meminta rokok pada teman dekatnya yang lain. Masalah merokok pada remaja ini sesuai dengan beberapa temuan penelitian yang menunjukkan bahwa: (1) merokok dapat dihubungkan dengan peningkatan angka morbiditas (kesakitan) dan mortalitas (kematian) terutama pada orang yang memulai merokok diusia muda ${ }^{15,16}$, (2) merokok merupakan sebuah kebiasaan yang susah untuk dihentikan ${ }^{17}$, (3) remaja yang mulai merokok lebih memungkinkan untuk mencoba dan menggunakan zat-zat terlarang seperti alkohol dan obat-obatan terlarang lainnya ${ }^{18,19}$, dan (4) usia penduduk Indonesia yang merokok sudah mulai menurun pada usia remaja dan bahkan beberapa kasus terjadi pada anak-anak ${ }^{20,21}$.

\section{KESIMPULAN}

Berdasarkan uraian diatas, kesimpulan dalam penelitian ini adalah:

1. Ada hubungan yang signifikan negatif antara pengetahuan remaja tentang rokok dengan perilaku merokok remaja di Kulonprogo Yogyakarta.

2. Ada hubungan yang signifikan positif antara umur remaja dengan perilaku merokok remaja di Kulonprogo Yogyakarta.

3. Ada hubungan yang signifikan positif antara uang saku remaja dengan perilaku merokok remaja di Kulonprogo Yogyakarta.

\section{KEPUSTAKAAN}

1. Dinas Kesehatan DIY. 2015a. Rumah Tangga Sehat dengan Perilaku Hidup Bersih dan Sehat. Yogyakarta.

2. -------, 2015b. Survey Rumah Tangga Berperilaku Hidup Bersih dan Sehat di Daerah Istimewa Yogyakarta. Yogyakarta.

3. Helman, CG. 1994. Cultur, Health and Illness. Oxford: Butterworth-Heinemann Ltd.

4. Kedaulatan Rakyat, 21 Maret 2018, Perokok usia dini, DIY Urutan Ke-4. Yogyakarta.

5. Wardoyo, H. 2017. Kebanyakan dari Pedesaan, Tinggi Jumlah Perokok Remaja di Kulonprogo. Yogyakarta: Harian Kedaulatan Rakyat. 03 Juni 2017.

6. Islamuddin, H. 2012. Psikologi Pendidikan. Yogyakarta: Pustaka Pelajar.

7. Hurlock, E.B. 2011. Psikologi Perkembangan Suatu Pendekatan Sepanjang Rentang Kehidupan. Edisi ke lima. Jakarta: Erlangga.

8. Crain, W. 2014. Teori Perkembangan Konsep dan Aplikasi. Edisi ketiga. Yogyakarta: Pustaka Pelajar.

9. Effendi, S dan Tukiran. 2012. Metode Penelitian Survei. Jakarta: LP3S.

10. Purwanto, N. 2007. Psikologi Pendidikan. Bandung: PT Rodakarya.

11. Soetjiningsih. 2010. Tumbuh Kembang Remaja dan Permasalahannya. Jakarta: Sagung Seto.

12. Suharmiati; Handajani, L dan Handajani, A. 2010. "Hubungan pola penggunaan rokok dengan tingkat kejadian penyakit asma". Buletin Penelitian Sistem Kesehatan. Volume 13 No. 4 Oktober 2010. diakses 20 Juli 2017.

13. Nurrahmah. 2014. "Pengaruh rokok terhadap kesehatan dan pembentukan karakter manusia". Prosiding seminar Nasional Pendidikan Karakter. Volume 1 Nomer 1. diakses 20 Juli 2017. 
14. Kemenkes RI. 2006. Panduan Pembinaan Perilaku Hidup Bersih dan Sehat di Rumah Tangga Melalui TIM Penggerak PKK. Jakarta: Kementerian Kesehatan Republik Indonesia

15. Wilson, L.M; Tang, E.A; Chander, G; Hutton, H.E; Odelola, O.A; Elf, J.L.; Stoddard, B.M.H; Bass, E.B; Little, E.A; Haberl, E.B and Apelberg, B.J. 2012. "Impact of Tobacco Control Interventions on Smoking Initiation, Cessation, and Prevalence: A Systematic Review". Journal of Environmental and Public Health . diakses pada tanggal 04 Agustus 2017.

16. Sajinadiyasa, I.G.K; Bagiada, I.M dan Rai, I.B.N. 2010. "Prevalensi dan resiko merokok terhadap penyakit paru di poliklinik paru Rumah Sakit Umum Pusat Sanglah Denpasar". Jurnal Penyakit Dalam. Volume 11 Nomer 2 Mei 2010. dikases 20 Juli 2017.

17. Xu, X; Liu, L; Sharma, $M$ and Zhao, Y. 2015. "Smoking-Related Knowledge, Attitudes, Behaviors, Smoking Cessation Idea and Education Level among Young Adult Male Smokers in Chongqing, China". International Journal of Environmental Research and Public Health. 16 Februari 2015, diakses 18 April 2017.
18. Nguyen, L.T; Rahman, Z; Emerson, M.R and Nguyen, M.H. 2012. "Cigarette Smoking and Drinking Behavior of Migrant Adolescents and Young Adults in Hanoi, Vietnam". Journal of Adolescent Health. Elsevier. diakses 18 April 2017.

19. Moore, T.J; Furberg, T.J; Glenmullen, J; Maltsbelger, J.T and Singh, S. 2011. "Suicidal Behavior and Depression in Smoking Cessation Treatments". Plos one. November 2011. Volume 6. diakses pada tanggal 04 Agustus 2017.

20. Memon, A; Moody, P.M; Sugathan, T.N; Gerges, N.E; Bustan, M.A; Shatti, A.A and Jazzaf, H.A. 2000. "Epidemiology of smoking among Kuwait adults: prevalence, characteristics, and attitudes". Bulletin of the World Health Organization. 2000. diakses pada tanggal 04 Agustus 2017.

21. Goldade, K; Choi, K; Bernat, D.H; Klein, E.G; Okuyemi, K.S and Forster, J. 2012. "Multilevel predictors of smoking initiation among adolescents: Findings from the Minnesota Adolescent Community Cohort (MACC) study". Preventive Medicine. Elsevier. diakses 18 April 2017. 